\title{
Toward a Bias Corrected Currency Equivalent Index
}

\author{
William A. Barnett ${ }^{\mathrm{a}}$, John W. Keating ${ }^{\mathrm{a}}$, Logan J. Kelly ${ }^{\mathrm{b}, *}$ \\ ${ }^{a}$ University of Kansas, Department of Economics, Lawrence, KS 66045 \\ ${ }^{\mathrm{b}}$ Bryant University, Department of Economics, Smithfield, RI 02917 \\ e-mail: lkelly@bryant.edu Ph: (401)232-6897 Fax: (401)232-6319
}

\begin{abstract}
Measuring the economic stock of money, defined to be the present value of current and future monetary service flows, is a difficult asset pricing problem, because most monetary assets yield interest. Thus, an interest yielding monetary asset is a joint product: a durable good providing a monetary service flow and a financial asset yielding a return. The currency equilivant index provides an elegant solution, but it does so by making strong assumptions about expectations of future monetary service flows. These assumptions cause the currency equivalent index to exhibit significant downward bias. In this paper, we propose an extension to the currency equivalent index that will correct for a significant amount of this bias.
\end{abstract}

Key words: Currency Equilivant Index, Monetary Aggregation, Money Stock JEL classification codes: E49

\section{Introduction}

Measuring the economic stock of money (ESM), defined by Barnett (1991) to be the present value of current and future monetary service flows, is a difficult asset pricing problem, because most monetary assets yield interest. Thus, an interest yielding monetary asset is a joint product: a durable good providing a monetary service flow and a financial asset yielding a return. Barnett showed that the currency equivalent index (CE), first suggested by Hutt (1963) and formally derived by Rotemberg et al. (1995), provides an elegant solution, but it does so by making strong assumptions about expectations of future monetary service flows. Barnett et al. (2005) found that these assumptions

* Corresponding author.

Preprint submitted to Economics Letters

September 24, 2007 
cause the CE to exhibit significant downward bias. In this paper, we propose an extension to the $\mathrm{CE}$ that will correct for a significant amount of this bias. We shall call this new index number the modified currency equivalent index (MCE).

Aggregation theoretic measures of the ESM, like the CE and the MCE, differ significantly from the Federal Reserve's official measure of the capital stock of money, which uses the usual simple sum aggregation methodology. Because interest yielding monetary assets are joint products, yielding both monetary and investment services, simple sum aggregation confounds the present value of the investment yield of monetary assets and the ESM. This confounding causes the simple sum aggregates to overstate and to smooth the dynamics of the true ESM This confounding may also explain the poor performance of the official monetary aggregates in forecasting and policy applications.

\section{The Economic Capital Stock of Money}

\subsection{Definition Under Perfect Foresight}

Following Barnett (1978), let the representative consumer's current period intertemporal utility function, $u_{t}$, be weakly separable in each period's consumption of goods and monetary assets. ${ }^{1}$ Let period $t$ be the current time period, and let $T$ be the length of the planning horizon, possibly infinity, such that the representative consumer plans for all periods, $s=t, t+1, \ldots t+T$. Now define the following variables for period $s$ :

$$
\begin{aligned}
C_{s}= & (I \times 1) \text { vector of planned per capital consumption of goods and } \\
& \text { services during period } s, \\
p_{s}= & (I \times 1) \text { vector of goods and services expected prices and of durable } \\
& \text { goods expected rental prices, } \\
p_{s}^{*}= & \text { the true cost of living index, } \\
m_{s}= & (N \times 1) \text { vector of planned real balances of monetary assets, } \\
M_{s}= & (N \times 1) \text { vector of planned nominal balances of monetary assets, } \\
r_{s}= & (N \times 1) \text { vector of expected nominal holding period yields on mon- } \\
& \text { etary assets, } \\
R_{s}= & \text { the expected nominal one-period holding yield on the benchmark } \\
& \text { asset. }
\end{aligned}
$$

$\overline{1}$ It is worth noting that $u_{t}$ is not an elementary utility function, since it contains monetary assets. However, Arrow and Hahn (1971) proved that if money has positive value, then there exists a derived utility function containing money. 
Further assume that there exists $p_{s}^{*}=p_{s}^{*}\left(p_{s}\right)$, the true cost of living index, which can be used to deflate nominal values in period $s$. Barnett (1991) recursively combines the $T+1$-period budget constraints from the representative agents problem into the single discounted Fisherine wealth constraint. From this discounted Fisherine wealth constraint, Barnett defines the ESM, $V_{t}$, as

$$
V_{t} \equiv \sum_{s=t}^{T} \sum_{n=1}^{N}\left[\frac{p_{s}^{*}}{\rho_{s}}-\frac{p_{s}^{*}\left(1+r_{n, s}\right)}{\rho_{s+1}}\right] m_{n s}
$$

where the discount rate for period $s$ is

$$
\rho_{s}=\left\{\begin{array}{ll}
1 & s=t \\
\prod_{u=t}^{s-1}\left(1+R_{u}\right) & s \neq t
\end{array} .\right.
$$

Following Barnett et al. (2005), (1) can be rewritten as

$$
V_{t}=\sum_{s=t}^{\infty} \sum_{n=1}^{N}\left[m_{n s}\left(p_{s}^{*} \cdot \frac{R_{s}+r_{n, s}}{1+R_{s}}\right) \frac{1}{\rho_{s}}\right]=\sum_{s=t}^{\infty} \frac{T E_{s}}{\rho_{s}},
$$

where $T E_{s}$ is the total nominal expenditure on monetary services in period $s$, and $T$ is allowed to approach infinity.

\subsection{Extension to Uncertainty}

Assuming inter-temporal strong separability, Barnett (1995) and Barnett et al. (1997) showed that all the results on user cost and Divisia aggregation can be extended to the case of risk neutrality by replacing all random variables with their expectations. Thus, applying the consumption-based capital asset pricing model theory, the formulas for the economic capital stock of money under inter-temporal strong separability becomes

$$
V_{t}=E_{t}\left(\sum_{s=t}^{\infty} \Gamma_{s} T E_{s}\right)
$$

where

$$
\Gamma_{s}=\beta^{s-t} \frac{\partial u}{\partial C_{s}} / \frac{\partial u}{\partial C_{t}}
$$

is the subjectively-discounted marginal rate of inter-temporal substitution between consumption in the current period $t$ and the future period $s .^{2}$

$\overline{2}$ See Blanchard and Fischer (1989) section 6.3 and Cochrane (2005). 


\section{Bias Correction of the Currency Equivalent Index}

\subsection{Source of Bias Observed in Currency Equivalent Index}

The CE is a special case of the ESM. To see this, follow Barnett (1991) by assuming that $R_{s}=R_{t}, r_{n s}=r_{n t}$, and $M_{n s}=M_{n t}$ for all $n \in N$ and $s=$ $t, t+1, t+2 \ldots$ Then (1) can be written

$$
V_{t}=\sum_{s=t}^{\infty} \sum_{n=1}^{N}\left[\frac{R_{t}-r_{n t}}{\prod_{u=t}^{s}\left(1+R_{t}\right)}\right] M_{n t}=\sum_{n=1}^{N}\left[\frac{R_{t}-r_{n t}}{R^{s-t+1}}\right] M_{n t}=V_{t}^{C E}
$$

Equation (6) is the CE derived by Rotemberg et al. (1995). Thus, to calculate the $\mathrm{CE}$, we assume that total expenditure on monetary assets follows a martingale process. Barnett et al. (2005) showed that this assumption results in a small downward bias because total expenditure on monetary services trends upwards over time (see figure 1). ${ }^{3}$ Thus, as we move further into the future, the assumptions upon which the CE rests do not match an important characteristic of the data.

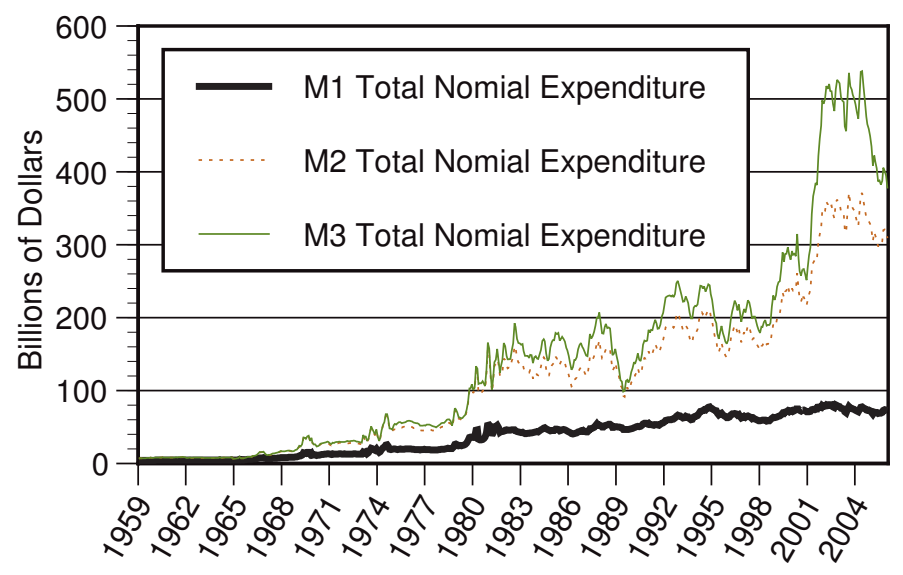

Figure 1. Total Expenditure on Monetary Service

\subsection{Derivation of Bias Corrected Currency Equivalent Index}

We begin by assuming that the expectation of the stochastic discount factor in time period $t$ is

$$
E_{t}\left(\Gamma_{s}\right)=\prod_{u=t}^{s}\left[1+E_{t}\left(R_{u}\right)\right]^{-1}
$$

3 Figures 2, 4 and 6 show the deviation of the CE from the perfect foresight ESM, calculated by Barnett et al. (2005). 
Then (4) becomes

$$
V_{t}=\sum_{s=t}^{\infty} \frac{E_{t}\left(T E_{s}\right)}{\prod_{u=t}^{s}\left[1+E_{t}\left(R_{u}\right)\right]}+\operatorname{cov}(T E, \Gamma) .
$$

Now assume that expectations about the benchmark rate are stationary, so that $R_{s}=R_{t}$ for all $s \geq t$, and that $\operatorname{cov}(T E, \Gamma)=0$. Then we have

$$
V_{t}=\sum_{s=t}^{\infty} \frac{E_{t}\left(T E_{s}\right)}{\left(1+R_{t}\right)^{s-t}} \text {. }
$$

Finally, assume that

$$
E_{t}\left(T E_{s}\right)=T E_{t}\left(1+g_{t}\right)^{s-t}
$$

where $g_{t}$ is the average growth rate of total expenditure on monetary services at time $t$. Combining (7) and (8) yields

$$
V_{t}^{M C E}=\frac{T E_{t}\left(1+R_{t}\right)}{R_{t}-g_{t}}
$$

which we shall call the modified currency equivalent index (MCE). Note that if $g_{t}$ is zero for all $t$, then $V_{t}^{M C E}$ reduces to $V_{t}^{C E}$.

\section{Results}

In order to compare the performance of the MCE relative to the $\mathrm{CE}$, we compare each to the perfect foresight ESM calculated by Barnett et al. (2005). ${ }^{4}$ Figures 2, 4 and 6 show the percentage deviation of the MCE from PF, which is the perfect foresight ESM, as compared to the CE. Table 1 summarizes these results. First we examine the mean percent error (MPE). At the M1 level of aggregation, the MCE overstates by an average of 3.015; and, at the M2 and M3 levels of aggregation, the MCE understates by an average of 7.254 percent, and 5.807 percent, respectively. Thus, at the M1, M2 and M3 levels of aggregation, the MCE eliminates on average 46.45 percent, 55.37 percent and 62.85 percent, respectively, of the systematic bias observed in the $\mathrm{CE}$.

Table 1 also compares the performance of the MCE to that of the CE by measuring the mean absolute percent error (MAPE) and root mean squared error (RMSE) of both the MCE and the CE relative to the perfect foresight ESM. The MCE is found to be superior to the CE by all three criteria at all

$\overline{4}$ The results are generated using Ox version 4.00 (Doornik, 2006). See http://www.doornik.com for further information. 
three levels of aggregation. Figures 3, 5 and 7 plot the economic capital stock of money at M1, M2 and M3 levels of aggregation, respectively, as measured by the MCE, CE and perfect foresight ESM.

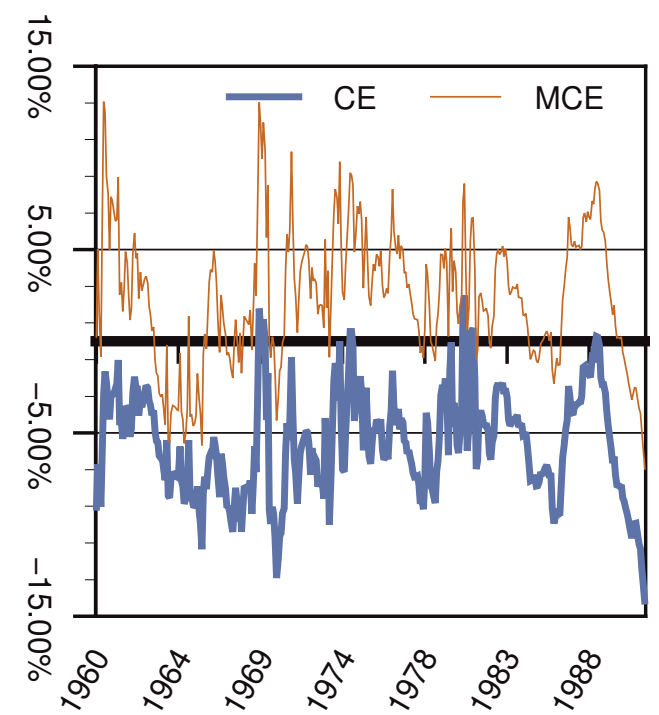

Figure 2. Percent Error of the MCE as Compared to the CE Relative to Perfect Foresight ESM (M1)

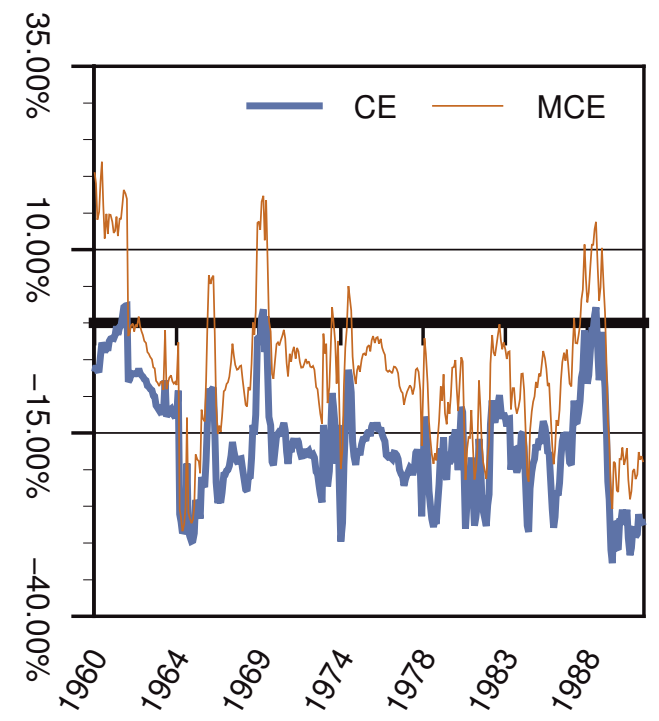

Figure 4. Percent Error of the MCE as Compared to the CE Relative to Perfect Foresight ESM (M2)

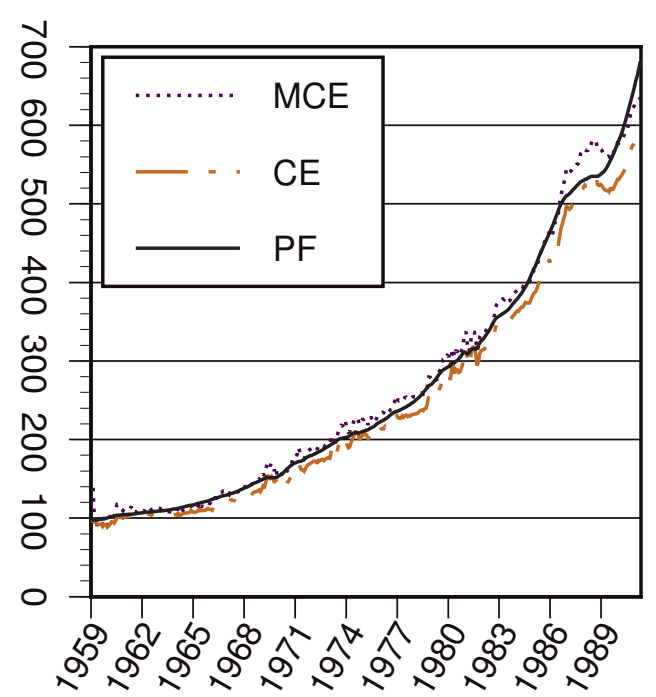

Figure 3. Economic Capital Stock of Money (M1)

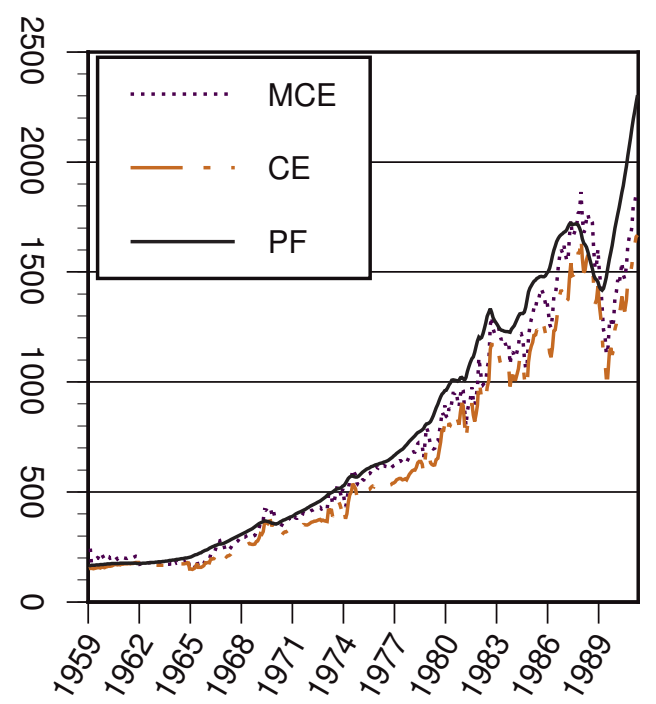

Figure 5. Economic Capital Stock of Money (M2) 


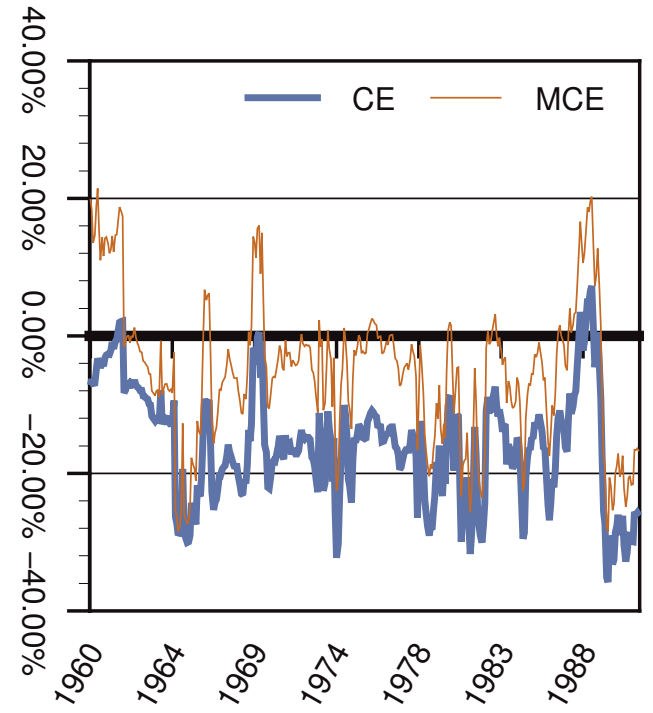

Figure 6. Percent Error of the MCE as Compared to the CE Relative to Perfect Foresight ESM (M3)

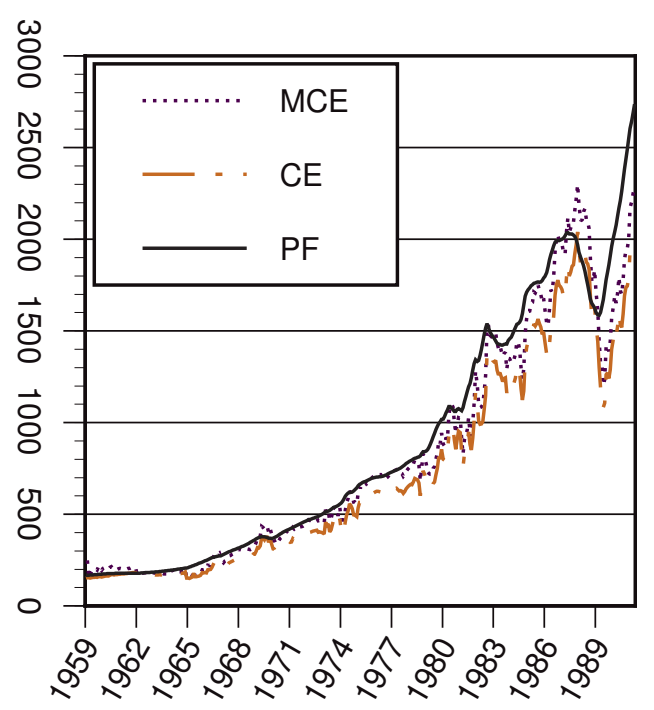

Figure 7. Economic Capital Stock of Money (M3)

Table 1

Comparison of MCE to CE relative to perfect foresight ESM

\begin{tabular}{lrrr}
\hline & MPE & MAPE & RMSE \\
\hline MCE1 & $3.015 \%$ & $3.539 \%$ & 13.219 \\
MCE2 & $-7.254 \%$ & $9.633 \%$ & 127.671 \\
MCE3 & $-5.870 \%$ & $9.187 \%$ & 152.903 \\
CE1 & $-5.630 \%$ & $5.688 \%$ & 21.055 \\
CE2 & $-16.253 \%$ & $16.330 \%$ & 197.048 \\
CE3 & $-15.802 \%$ & $16.010 \%$ & 224.892 \\
\hline
\end{tabular}

\section{Conclusion}

Aggregation theoretic measures of the economic stock of money require forecasting future monetary service flows. The currency equivalent index greatly simplifies the procedure of discounting future monetary service by assuming that future monetary service flows remain constant at current levels. This assumption produced reluctance to accept the currency equivalent index as a measure of the money stock. However, Barnett et al. (2005) showed that the resulting bias is relatively small, when compared to the bias observed in the simple sum aggregates. Moreover, we find that by allowing total expenditure on monetary services to increase over time, the bias observed in the currency equivalent index can be reduced by nearly $63 \%$.

While the modified currency equivalent index does exhibit a small bias, it is a significant improvement over the currency equivalent index. Moreover, 
both indices are very large improvements over the simple sum aggregates. Hence, we conclude that while more sophisticated forecasting methodology may lead to slightly improved measures of the money stock, the modified currency equivalent index provides an easily calculated, internally consistent measure of the economic stock of money and improves upon both the currency equivalent and the simple sum indices.

\section{References}

Arrow, K. J., Hahn, G. H., 1971. General Competitive Analysis. San Francisco: Holden-Day.

Barnett, W. A., 1978. The user cost of money. Economics Letters 1 (2), 145149. Reprinted in The Theory of Monetary Aggregation, William Barnett and Apostolos Serletis (eds.), 2000, Amsterdam, 6-10.

Barnett, W. A., 1991. A reply to Julio J. Rotemberg. In: Belongia, M. T. (Ed.), Monetary Policy on the 75th Anniversary of the Federal Reserve System. Proceedings of the Fourteenth Annual Economic Policy Conference of the Federal Reserve Bank of St. Louis, Kluwer, pp. 189-222. Reprinted in The Theory of Monetary Aggregation, William Barnett and Apostolos Serletis (eds.), 2000, Amsterdam, 296-306.

Barnett, W. A., 1995. Exact aggregation under risk. In: Barnett, W. A., Salles, M., Moulin, H., Schofield, N. (Eds.), Social Choice, Welfare and Ethics. Proceedings of the Eighth International Symposium in Economic Theory and Econometrics, Cambridge University Press, pp. 353-374. Reprinted in The Theory of Monetary Aggregation, William Barnett and Apostolos Serletis (eds.), 2000, Amsterdam, 195-216.

Barnett, W. A., Chae, U., Keating, J. W., July 2005. The discounted economic stock of money with VAR forecasting. Annals of Finance 2 (2), 229-258.

Barnett, W. A., Liu, Y., Jensen, M., 1997. CAPM risk adjustment for exact aggregation over financial assets. Macroeconomic Dynamics 1 (2), 485-512. Reprinted in The Theory of Monetary Aggregation, William Barnett and Apostolos Serletis (eds.), 2000, Amsterdam, 245-273.

Blanchard, O. J., Fischer, S., 1989. Lectures on Macroeconomics. Cambridge: MIT Press.

Cochrane, J. H., 2005. Asset Pricing, Revised Edition. Princeton: Princeton University Press.

Doornik, J. A., 2006. Ox-An Object Oriented Matrix Programming Language. London: Timberlake Consultants Press and Oxford: www.doornik.com.

Hutt, W. H., 1963. Keynesianism - Retrospect and Prospect. Chicago: Regnery.

Rotemberg, J. J., Driscoll, J. C., Poterba, J. M., 1995. Money, output, and prices: Evidence from a new monetary aggregate. Journal of Business and Economic Statistics 13 (1), 67-83. 